
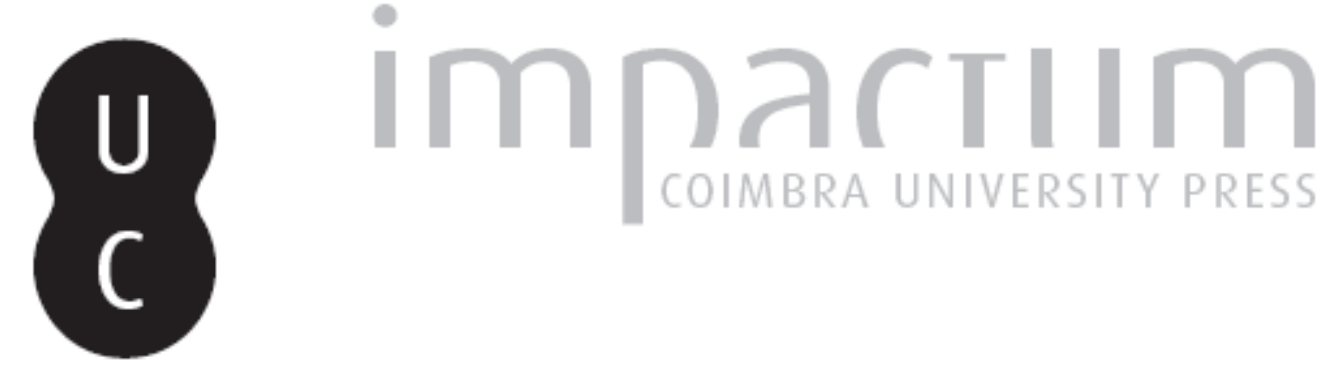

\title{
A importância da radiografia odontológica em perícia para avaliação do nexo de causalidade em acidente de trabalho: notas no contexto da realidade brasileira
}

Autor(es): $\quad$ Bouchardet, FCH; Yamauchi, N; Oliveira, TA; Vieira, DN; Manzi, FR

Publicado por: Imprensa da Universidade de Coimbra

URL

persistente:

URI:http://hdl.handle.net/10316.2/42161

DOI:

DOI:http://dx.doi.org/10.14195/1647-8630_26_5

Accessed : $\quad$ 26-Apr-2023 14:44:16

A navegação consulta e descarregamento dos títulos inseridos nas Bibliotecas Digitais UC Digitalis, UC Pombalina e UC Impactum, pressupõem a aceitação plena e sem reservas dos Termos e Condições de Uso destas Bibliotecas Digitais, disponíveis em https://digitalis.uc.pt/pt-pt/termos.

Conforme exposto nos referidos Termos e Condições de Uso, o descarregamento de títulos de acesso restrito requer uma licença válida de autorização devendo o utilizador aceder ao(s) documento(s) a partir de um endereço de IP da instituição detentora da supramencionada licença.

Ao utilizador é apenas permitido o descarregamento para uso pessoal, pelo que o emprego do(s) título(s) descarregado(s) para outro fim, designadamente comercial, carece de autorização do respetivo autor ou editor da obra.

Na medida em que todas as obras da UC Digitalis se encontram protegidas pelo Código do Direito de Autor e Direitos Conexos e demais legislação aplicável, toda a cópia, parcial ou total, deste documento, nos casos em que é legalmente admitida, deverá conter ou fazer-se acompanhar por este aviso.

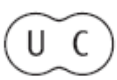




\section{A importância da radiografia odontológica em perícia para avaliação do nexo de causalidade em acidente de trabalho Notas no contexto da realidade brasileira}

Bouchardet $\mathrm{FCH}^{1}$, Yamauchi $\mathrm{N}^{2}$, Oliveira $\mathrm{TA}^{2}$, Vieira $\mathrm{DN}^{3}$, Manzi $\mathrm{FR}^{4}$

Resumo: A importância da radiografia odontológica em perícia para avaliação do nexo de causalidade em acidente de trabalho. Notas no contexto da realidade brasileira.

No Brasil, as perícias dividem-se em dois grupos: extrajudiciais e judiciais. 0 nexo de causalidade técnico é o ponto chave sobre o qual assenta a avaliação pericial do dano corporal. Analisá-lo e estabelecê-lo com segurança pode ser tarefa complexa. Se não existe prova ou desaparece a noção de causalidade médico-legal, desaparece o motivo da reclamação. Há a necessidade de se estabelecer o nexo de causalidade no acidente de trabalho, vinculando a lesão ao próprio acidente. 0 estado anterior não assinalado é uma das armadilhas da avaliação do dano corporal e o especialista deve estar atento a esta possibilidade. Neste trabalho analisou-se dois casos periciais em que o exame radiológico foi indispensável para avaliar a relação causal do acidente relatado pelo trabalhador e as queixas em decorrência do acidente. Assim, as radiografias odontológicas vêm sendo utilizadas como importante instrumento no estabelecimento do nexo de causalidade e na avaliação do estado anterior das condições bucais dos trabalhadores nas situações de acidentes de trabalho.

Palavras-chave: Odontologia legal; radiologia odontológica; dano corporal; nexo de causalidade.

1 Doutora em Ciências da Saúde e Mestre em Medicina Legal e Ciências Forenses pela Univ. de Coimbra Portugal. Coordenadora da especialização de Odontologia Legal da PUC-Minas.

2 Especialista em Medicina do Trabalho e Pós-Graduada em Avaliação do Dano Corporal Pós-Traumático Delegação do Centro do Instituto Nacional de Medina Legal, IP

3 Profesor Catedrático da Faculdade de Medicina da Universdade de Coimbra

4 Professor Adjunto de Radiologia da PUC-Minas. Coordenador do Mestrado da PUC-Minas - Ênfase Radiologia Odontológica 
Summary: The importance of dental radiography in expertise performed for evaluation the causality link in industrial accident. Notes in the context of Brazilian reality.

Expertise are divided into two groups in Brazil: extrajudicial and judicial. The causality link is the key factor on which the expert analysis of bodily damage are based. Establishing it with certainty can be a very complex task. If there is no proof, or the notion of medical imputability disappears, the motive for the complaint also disappears. It is necessary to establish the causality link in accidents in the workplace, linking the damage to the accident itself. The non-marked previous condition can be a trap in bodily damage evaluation and the expert should be observant of this possibility. This present article shows the analysis of two cases where the dental radiological examination was indispensable to refute the causality link between the accident described by the worker and his complaints. Dental radiology can be important instrumental in the analysis of the previous condition of oral conditions of workers in situations of industrial accidents.

Key-words: Legal dentistry; dental radiology; body damage; causality link.

No Brasil, as perícias dividem-se em dois grupos: extrajudiciais e judiciais. As extrajudiciais são, como próprio nome sugere, as realizadas fora do âmbito judicial, ou seja, aquelas perícias que não são levadas ao conhecimento de um juiz ou de um outro elemento do Poder Judiciário, para avaliação e decisão de causa. Podem citar-se, como exemplo, as perícias realizadas diretamente pelos clínicos de seguradoras para os seus segurados após um acidente de qualquer natureza, as realizadas pelo corpo médico de uma instituição com a finalidade de admissão de candidato em concurso, ou as realizadas pelos órgãos previdenciários tendo em vista a concessão de determinados benefícios, entre muitas outras que se resolvem sem a necessidade de intervenção judicial..$^{1,2}$ No âmbito judicial para que o lesado tenha direito a uma indemnização, é imprescindível a caracterização dos pressupostos da responsabilidade civil: facto, dano, ilicitude, culpa e nexo de causalidade.

De acordo com a súmula $\mathrm{n}^{\circ} 15$, de 14 de novembro de 1990, o Superior Tribunal de Justiça Brasileiro determinava que "compete à Justiça Estadual processar e julgar os litígios decorrentes de acidente do trabalho". A emenda constitucional $\mathrm{n}^{\circ} 45$, de 30 de dezembro de 2004, reforça a anterior, continuando a Justiça do Estado a determinar as ações de indemnização por dano moral ou patrimonial, decorrentes da relação de trabalho. ${ }^{3}$

Conforme dispõe o art. 19 da Lei $\mathrm{n}^{\circ}$ 8.213/91 do Brasil, "acidente de trabalho" é o que ocorre pelo exercício do trabalho o serviço da empresa ou pelo exercício do trabalho dos segurados referidos no inciso VII do art. 
11 desta lei, provocando lesão corporal ou perturbação funcional que cause a morte ou a perda ou redução, permanente ou temporária, da capacidade para o trabalho". Por expressa determinação legal, as doenças profissionais e/ou ocupacionais equiparam-se a acidentes de trabalho., ${ }^{4,5}$

Nas ações indemnizatórias relacionadas com acidentes do trabalho e doenças ocupacionais é necessária a conjugação dos seguintes componentes: o sinistro e o nexo causal com a atividade, a sequela com redução ou eliminação da capacidade laboral, a culpa da empresa e as perdas morais e patrimoniais decorrentes. A culpa da empresa, por negligência ou omissão, pode ser presumida, competindo à própria empregadora o dever de provar o contrário. Vale o aproveitamento de todos os processos administrativos da autarquia previdenciária principalmente quando o instituto previdenciário tenha admitido o acidente de trabalho com nexo de causal com a sequela que apresenta o trabalhador, aposentando-os por invalidez ou concedendo auxílio-acidente. ${ }^{3}$

Sendo o nexo de causalidade médico-legal (a imputabilidade médica) o elemento chave sobre o qual assenta a avaliação pericial do dano corporal, a sua análise e estabelecimento seguro, pode constituir uma tarefa complexa. O estabelecimento do nexo de causalidade é, como sempre foi, um dos aspetos mais importantes da valoração de danos na pessoa. É a base da avaliação e, simultaneamente, o ponto de partida ou o ponto final da valoração médico-legal. É indispensável provar que a conduta ou fato objeto de litígio causou determinadas lesões ou sequelas ou a morte. Se não existe prova ou desaparece a noção de causalidade médico-legal, desaparece o motivo da reclamação.6 O nexo de causalidade técnico é a relação indispensável de causa e efeito; é a correlação que deve existir entre o traumatismo e o dano.

Neste texto, analisamos dois casos periciais em que o exame radiológico foi indispensável para o estabelecimento de um nexo de causalidade odontológico em trabalhadores envolvidos em acidente de trabalho.

\section{Caso Clínico 1}

Trabalhador com história de acidente de trabalho verificado em abril de 2014, quando, ao carregar caixas empilhadas uma sobre as outras acima da cabeça, uma destas caixas se desequilibrou e começou a cair. No impulso, de maneira involuntária, o trabalhador tentou agarrar a caixa, sendo atingido na região bucal. Segundo o relatório médico, o trabalhador comunicou imediatamente o evento ao encarregado, mas como não havia sangramento, 


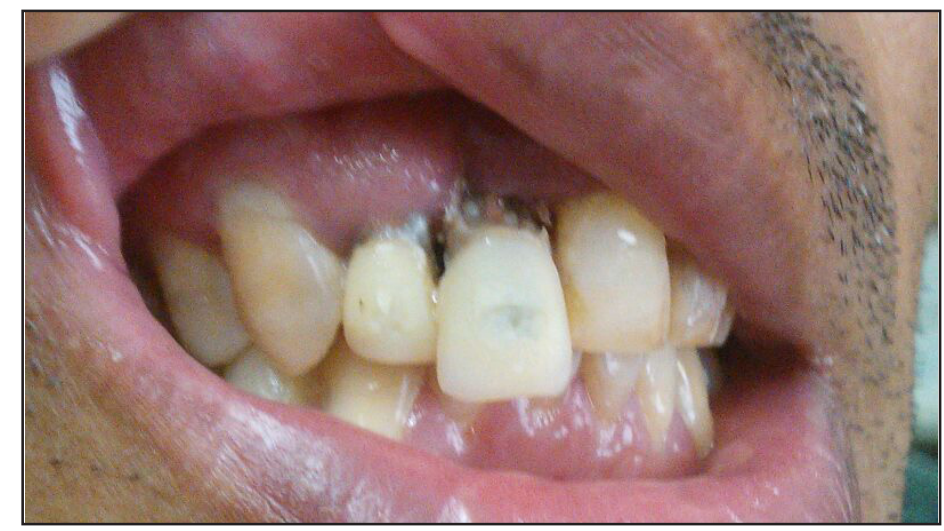

Fig. 1 Foto intra-bucal mostrando a extrusão e exposição radicular dos dentes 11 e 12, sendo mais evidente no dente 11 .

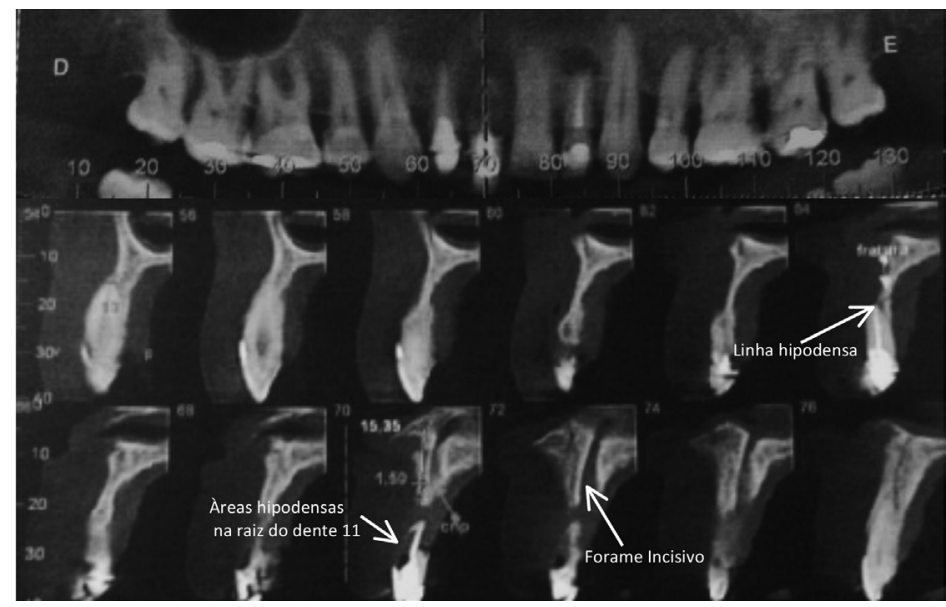

Fig. 2 Tomografia computadorizada mostrando a reconstrução panorâmica e sequência de cortes transversais. Note a linha hipodensa na região da maxila do lado direito sugestiva de fratura e áreas hipodensas na porção radicular do dente 11.

este considerou desnecessário o atendimento médico convencionado. Uma semana após o acidente, o trabalhador procurou o serviço médico afirmando que a lesão que apresentava na sua restauração dentária e as alterações nos seus dentes (Figura 1) teriam sido provocados pelo referido acidente.

$\mathrm{Na}$ tomografia computadorizada foram constatados comprometimento da raiz do dente 11 (áreas hipodensas ao longo desta raiz sugestiva de reabsorção 
radicular externa e/ou lesão cariosa) e presença de uma linha hipodensa na região anterior da maxila do lado direito, sugestivo de fratura no dente 12, além da redução de sua espessura e altura. Estas alterações são compatíveis com doença periodontal generalizada e processo inflamatório crônico.

Assim sendo, apesar da radiografia apresentar sinais de fratura recente no dente 12, não é possível afirmar ou negar que esta ocorreu devido ao traumatismo. As consequências podem ser explicadas por outros fatores, podendo o evento traumático ter precipitado a evolução da doença, mas sem ocupar papel primordial.

\section{Caso Clínico 2}

Trabalhador que refere acidente de trabalho em abril de 2011, tendo sido atingido na face, à direita, por estrutura metálica de camião. Afirmou que, como consequência do acidente, a sua prótese parcial removível superior se fraturou, deixando os dois dentes superiores presentes (13 e 27) abaulados (mobilidade moderada), sofrendo também um corte no lábio superior (Figura 3). Este indivíduo não apresentava os outros dentes superiores.
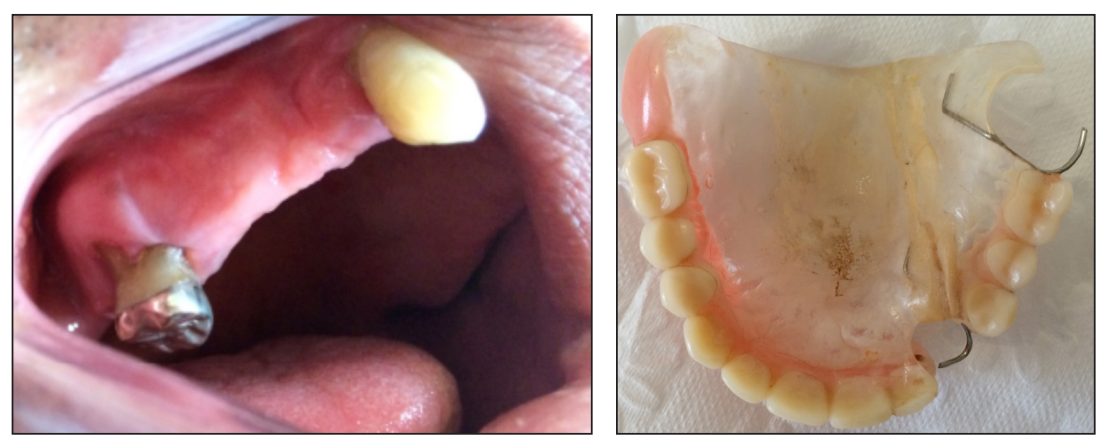

Figura 3: Foto intra-bucal mostrando as ausências dentárias e os dentes remanescentes com exposição radicular do dente 17. Note-se ainda, prótese parcial removível, ao lado, com visível linha de fratura colada com resina acrílica.

Ao exame clínico observou-se importante mobilidade dentária. Nas radiografias panorâmica e periapicais dos dentes superiores, foi constatada importante perda óssea horizontal generalizada e angular, além do envolvimento de furca do dente 17. Foi solicitada reabilitação oral total na arcada superior com implantes (Figura 4). 
Sabe-se que são necessários meses, ou até anos, para que tais reabsorções ósseas se desenvolvam até este estágio. Ou seja, esta condição periodontal não pode ter sido produzida em decorrência do trauma. As imagens radiográficas atuais são compatíveis com doença periodontal (doença pré-existente).

Os elementos permitem assim afirmar a existência de nexo de causalidade entre o acidente, a lesão da mucosa e a fratura da prótese dentária, mas sendo as alterações odontológicas apresentadas radiograficamente anteriores ao acidente. Não existe pois qualquer relação com os demais dentes perdidos previamente ao traumatismo.

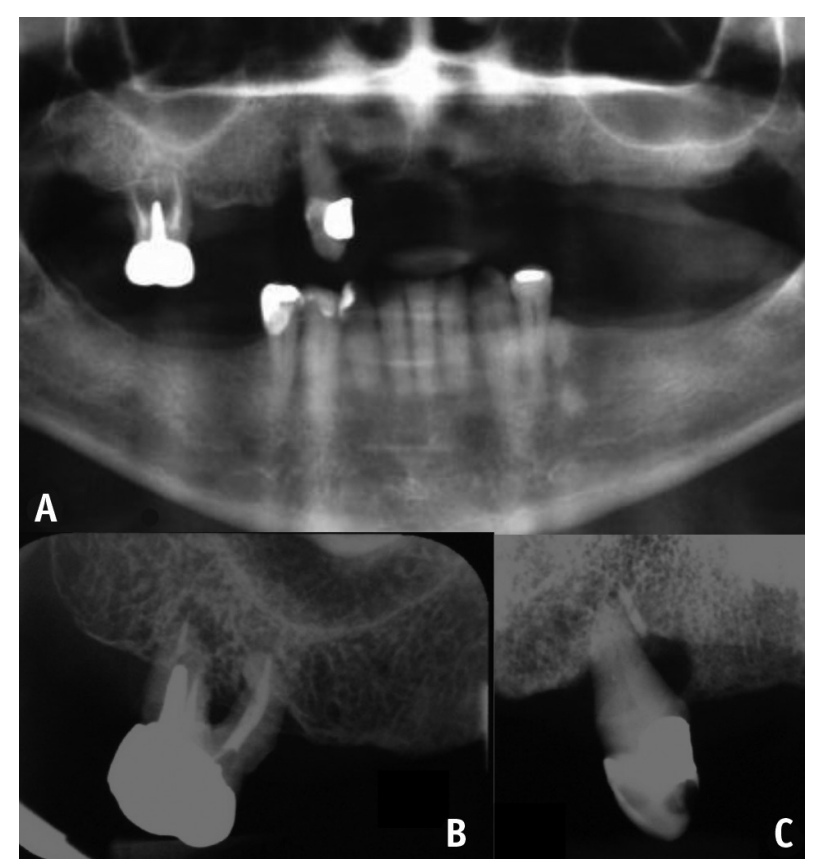

Fig. 4 A - Radiografia Panorâmica e B e C - Radiografias Periapicais mostrando a condição periodontal do paciente. Note a importante reabsorção óssea horizontal e angular, além do envolvimento de furca do dente 17.

\section{DISCUSSÃO}

Há a necessidade fundamental de se estabelecer o nexo de causalidade no acidente de trabalho, para uma vinculação da lesão ao próprio acidente. No acidente-tipo, não constitui habitualmente tarefa difícil estabelecer o 
nexo etiológico. O mesmo não pode todavia dizer-se no âmbito das doenças profissionais, não tanto pelo seu diagnóstico em si, mas, sobretudo, pela relação de causa e efeito. Haverá ainda, por fim, que avaliar a existência de determinadas condições de tempo e lugar, comprovando que o acidente de trabalho se deu em horário e local convenientes. ${ }^{7}$

A problemática do nexo de causalidade constitui assunto de particular relevância. É um momento decisivo para toda a perícia. Os principais erros de peritagem são erros de imputabilidade. É fundamental que se compreenda a diferença entre nexo de causalidade médica, que procura estabelecer uma relação entre a alteração da integridade física e psíquica de uma dada pessoa e um determinado evento, e o procedimento jurídico, que tem por missão atribuir as consequências dessa alteração ao responsável pelo evento, isto é, pelo ato ou omissão que provocou as lesões. ${ }^{10}$

Assim sendo, na sua abordagem, a primeira etapa consistirá em avaliar cientificamente se existe relação de causalidade entre o evento traumático e as lesões e/ou sequelas alegadas e constatadas. A ser possível essa relação, deve-se apreciar a imputabilidade, dispondo de certo número de critérios inicialmente definidos por Muller e Cordonnier, em 1925, e posteriormente divulgados como critérios de Simonin, em 1960. 8,9,10 $^{2}$

a) Natureza adequada do traumatismo para produzir as lesões evidenciadas;

b) Natureza adequada das lesões a uma etiologia traumática;

c) Adequação entre a sede do traumatismo e a sede da lesão;

d) Encadeamento anatomoclínico;

e) Adequação temporal;

f) Exclusão da preexistência do dano relativamente ao traumatismo;

g) Exclusão de uma causa estranha ao traumatismo.

Esses critérios, tal como assinalado por Barrot e Nicourt ${ }^{8,9,10}$ em 1986, envolvem três aspectos essenciais: o fator tempo (intervalo temporal de aparecimento e continuidade evolutiva), o fator espaço (localização das lesões e/ou sequelas) e o fator fisiopatológico (explicação patogênica das lesões e/ou sequelas, ou seja, a produção de uma alteração anatomoclínica).

O estado anterior não assinalado é uma das armadilhas da avaliação do dano corporal e o especialista deve estar atento a esta possibilidade. A vítima pode atribuir ao acidente doença de que já era portadora anteriormente e reivindicar indemnização. Uma anamnese detalhada, um exame clínico minucioso, um completo conhecimento das sequelas, uma cuidada análise da documentação existente e, sobretudo, a experiência e o não facilitar, são 
elementos que permitem contornar tal risco. Ao perito competirá assinalar, no seu relatório pericial, as discordâncias e incongruências constatadas na sequência destas diversas ponderações

A nível dentário a existência de um estado anterior dentário é particularmente frequente, dada a prevalência de cáries e de anomalias ortodônticas. Existem pois problemas particulares de imputabilidade, quando o perito desconhece o estado anterior e atribui ao traumatismo em questão todas consequências das lesões e tratamentos a serem realizados, em particular protéticos. Consequências e tratamentos que, por vezes, estão de fato ligados ao estado anterior.

A possibilidade de trabalhador que exerce a sua atividade em ambiente de risco ser afetado por uma doença profissional ou sofrer um acidente é concreta. $\mathrm{O}$ ambiente de trabalho tem uma relação direta com o surgimento de doenças e a possibilidade da ocorrência de acidentes. ${ }^{11}$ Os dentes e demais estruturas da cavidade oral podem ser lesados diretamente por agentes físicos, químicos, biológicos ou mecânicos.

Num estudo realizado no Hospital Municipal de Contagem - Minas Gerais, foram avaliadas 301 pacientes vítimas de acidentes de trabalho que recorreram ao serviço de urgência. Destes pacientes, a grande maioria era do sexo masculino $(90,69 \%)$, tendo sido atendidas apenas 28 mulheres $(9,31 \%)$. A faixa etária mais frequentemente envolvida foi a de 20-24 anos (69 casos-22,2\%), observando-se uma diminuição do número de casos com o avançar da idade. Os dias da semana em que houve mais acidentes foram as quintas e sextas-feiras, com 74 e 61 casos, respetivamente, provavelmente por serem os últimos dias de trabalho da semana e, consequentemente, estarem os trabalhadores já mais cansados e com menor capacidade de concentração, elementos facilitadores de acidentes. ${ }^{12}$

Pode-se afirmar que em ambos os casos as radiografias solicitadas para o exame pericial foram essenciais para avaliar a relação causal entre os traumatismos e as queixas decorrentes dos acidentes.

A natureza da causa lesiva não apresenta características que possam produzir as manifestações observadas. Entre o traumatismo e o dano a imputar-lhe, deve existir uma continuidade sintomatológica, uma sucessão de fatos fisiopatológicos que torne plausível e aceitável uma cadeia causal que vai do trauma ao resultado final, ${ }^{9}$ o que não se observa nos casos supracitados. O intervalo livre entre o traumatismo e o dano deve ser compatível e adequado a uma etiologia traumática. ${ }^{9}$ As alterações clínicas e radiográficas observadas confirmam a presença de um estado anterior patológico prévio ao evento traumático (doença periodontal pré-existente). 
Embora a decisão final não pertença ao perito, ele é o detentor de conhecimentos médico-legais e deve discutir a influência de determinada doença ou sequela na evolução de lesões subjacentes a um acidente. $O$ perito deve solicitar toda a documentação e antecedentes do caso, realizar uma anamnese exaustiva e praticar um exame clínico cuidadoso, procurando obter o apoio dos exames complementares que forem necessários uma adequada abordagem fisiopatológica dos fatos. ${ }^{13}$

\section{CONCLUSÃO}

A relação causa-efeito é, em muitas situações, absolutamente evidente, não suscitando qualquer dúvida; todavia, nalguns casos, sobretudo quando se sobrepõem múltiplas concausas, pode ser particularmente complicada e não permitir estabelecer com certeza tal relação. Habitualmente, os elementos que configuram o nexo de causalidade - como o tipo de traumatismo, a zona afetada, o tempo transcorrido, o tratamento, a evolução e as sequelas - guardam uma coerência interna que proporciona uma certeza absoluta ou quase absoluta sobre a relação causa-efeito.

As radiografias odontológicas constituem um instrumento indispensável no estabelecimento do nexo de causalidade e na avaliação do estado anterior das condições bucais dos trabalhadores em situações alegadamente decorrentes de acidentes de trabalho.

\section{Referências bibliográficas}

1. Camargo RMC. Medicina de seguro: estudo sobre a conceituação e área de competência médica no seguro privado. Rio de Janeiro: Fenaseg, 1991. 365p.

2. Menezes J, Paulino N. Sobre acidente de trabalho, incapacidade e invalidez. São Paulo: LTr, 2002; 85p.

3. Freudenthal SP. A evolução da indenização por acidente do trabalho. São Paulo: LTR, 2007; p.183.

4. Oliveira SG. Indenizações Por Acidente do Trabalho ou Doença Ocupacional - $8^{\mathrm{a}}$ edição. São Paulo: LTr, 2014

5. Brasil. Programa Trabalho Seguro - Programa Nacional de Prevenção de Acidentes de Trabalho. Disponível em: http://www.tst.jus.br/web/trabalhoseguro/resolucao

6. Mor G, Heurton B. Préjudices extrapatrimoniaux permanents. In: Mor G, Heurton B. Évaluation du préjudice corporal: stratégie d'indemnisation - méthodes d'évaluation. Paris: Delmas, 2011/2012; p. 460-92. 
7. França GV. Medicina legal. 9 ed. Rio de Janeiro: Guanabara Koogan; 2011. 694p.

8. Alonso JS. A avaliação do prejuízo estético. In: Vieira DN, Quintero JA. Aspectos práticos da avaliação do dano corporal em Direito Civil. Coimbra: Caixa Seguros e Imprensa da Universidade de Coimbra, 2008; p. 85-96.

9. Sá FO. Clínica médico-legal da reparação do dano corporal em Direito Civil. Coimbra: APADAC, cap III p. 33-34, 1992.

10. Vieira DN, Corte-Real F. Nexo de causalidade em avaliação do dano corporal. In: Vieira DN, Quintero JA. Aspectos práticos da avaliação do dano corporal em Direito Civil. Coimbra: Caixa Seguros e Imprensa da Universidade de Coimbra, 2008; p. 61-84.

11. Mello PBM. Odontologia do trabalho uma visão multidisciplinar. Rio de Janeiro: Rubio; 2006. 224p.

12. Silva AL et al. $\mathrm{O}$ acidente de trabalho na experiência cirúrgica de um hospital geral. Jornal Brasileiro de Medicina: JBM, Rio de Janeiro, v. 92, n. 3, p. 66-68, mar. 2007.

13. Calabuig G. Medicina Legal y Toxicologia $-6^{\mathrm{a}}$ ed. Barcelona: Masson, 2004. 